\title{
Corrigendum
}

\section{Corrigendum to "Optimal SES Selection Based on SVD and Its Application to Incipient Bearing Fault Diagnosis"}

\author{
Longlong Li $\mathbb{D}^{D}$, Yahui Cui $\mathbb{D}^{D}$, Runlin Chen, and Xiaolin Liu \\ School of Mechanical and Precision Instrument Engineering, Xi'an University of Technology, Xi'an, China \\ Correspondence should be addressed to Yahui Cui; cyhxut@xaut.edu.cn
}

Received 31 December 2018; Accepted 26 February 2019; Published 25 July 2019

Copyright (C) 2019 Longlong Li et al. This is an open access article distributed under the Creative Commons Attribution License, which permits unrestricted use, distribution, and reproduction in any medium, provided the original work is properly cited.

In the article titled "Optimal SES Selection Based on SVD and Its Application to Incipient Bearing Fault Diagnosis" [1], Dr. Longlong Li was incorrectly listed as the corresponding author. The corresponding author is Prof. Yahui Cui.

\section{References}

[1] L. Li, Y. Cui, R. Chen, and X. Liu, "Optimal SES selection based on SVD and its application to incipient bearing fault diagnosis," Shock and Vibration, vol. 2018, Article ID 8067416, 13 pages, 2018. 


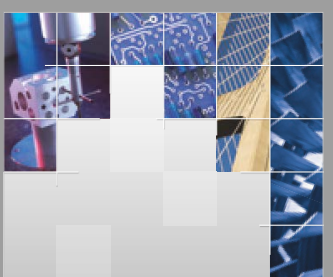

\section{Enfincering}
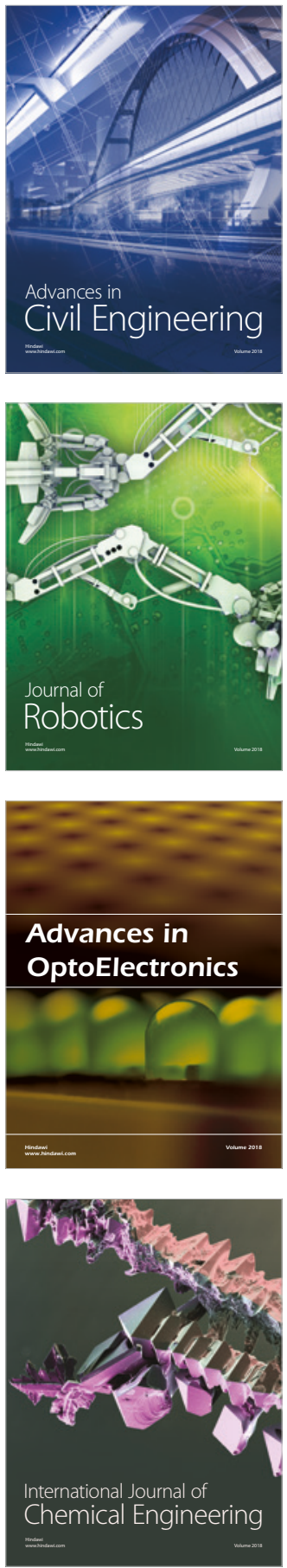

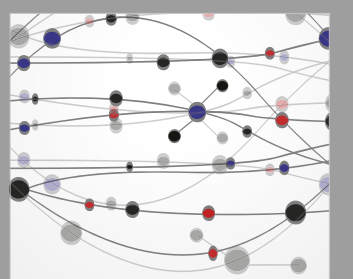

\section{Rotating \\ Machinery}

The Scientific World Journal

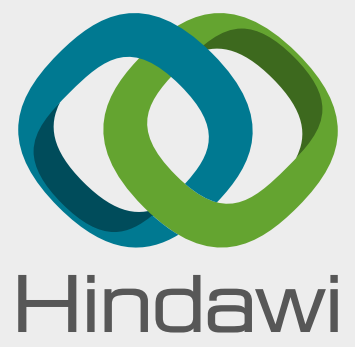

Submit your manuscripts at

www.hindawi.com
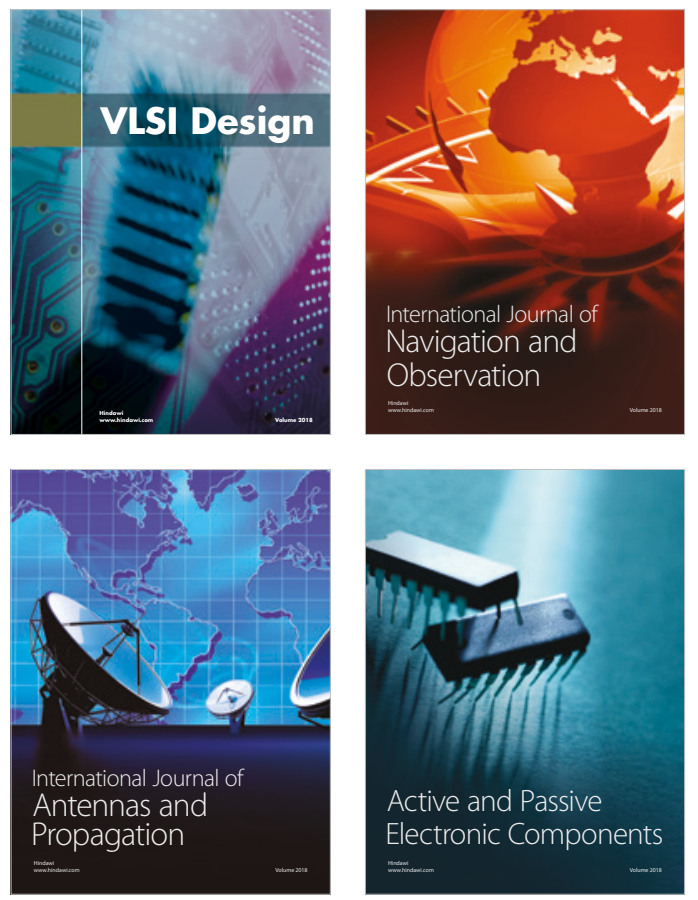
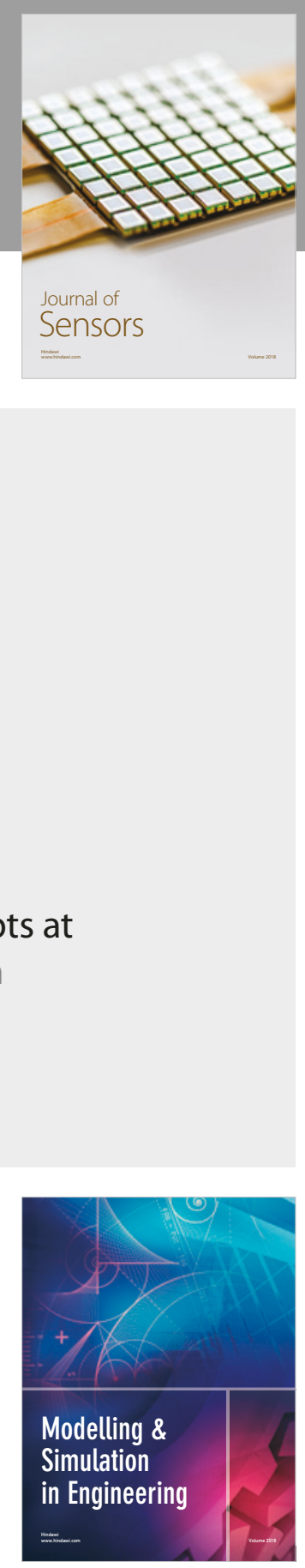

\section{Advances \\ Multimedia}
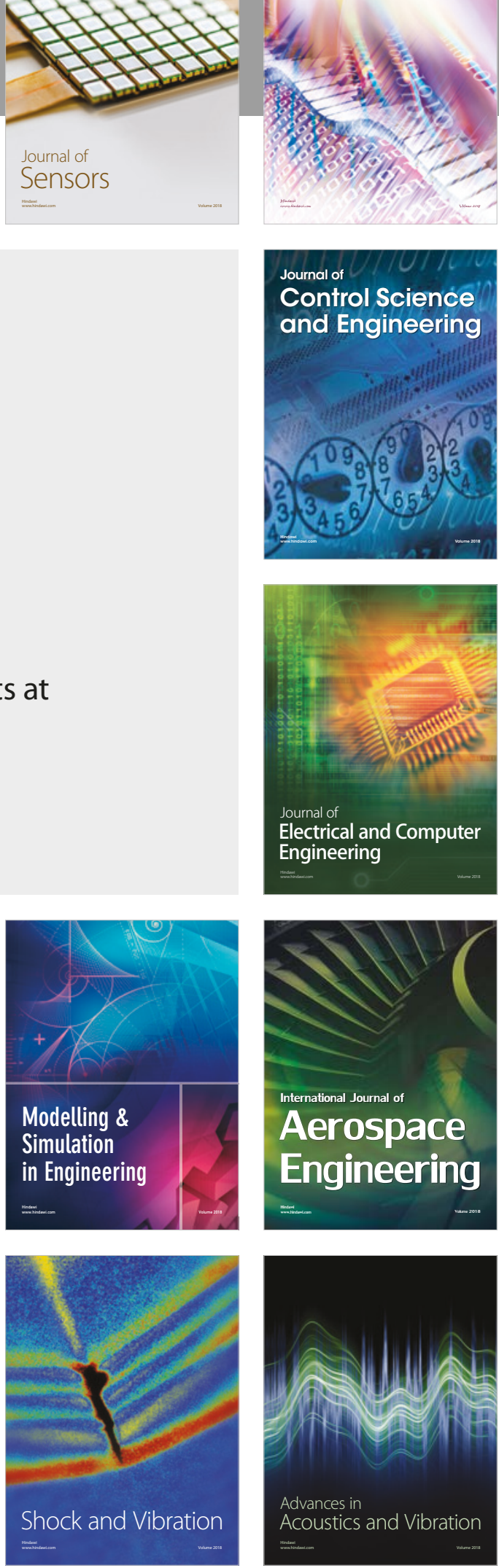